\title{
Pendampingan Kegiatan Seminar Hasil Penelitian Tindakan Kelas Pada Guru-Guru SDI Mbongawani
}

\author{
Nining Sar'iyyah ${ }^{*}$, Vivien Restianim² ${ }^{2}$, Manggu Ngguna Raji³, Yuliani Sepe \\ Wangge 4 , Gregorius Sebo Bito ${ }^{5}$ \\ 1,2,3,4,5Universitas Flores Ende \\ *Corresponding Author: sariyyah.nining@gmail.com
}

\begin{abstract}
Info Artike1 Diterima : 01/06/2021 Direvisi: 02/07/2021 Disetujui: 12/07/2021
Abstract. This activity aims to increase the understanding of SDI Mbongawani Ende teachers regarding the implementation of the seminar on the results of classroom action research. This activity also aims to help the teachers collect documents on the implementation of the seminar so that it can be used as evidence attached to the proposed promotion file. This activity was attended by teachers and principals of SDI Mbongawani, lecturers, group heads and teachers from related clusters. This activity was carried out in two stages, namely the preparation stage and the seminar implementation stage. At each stage, teachers are guided and trained to prepare, implement and document evidence of classroom action research seminars. The results of this activity have an impact on increasing the understanding of SDI Mbongawani teachers regarding the implementation of the seminar on the results of classroom action research.
\end{abstract}

Keywords: Mentoring, Seminar, Classroom Action Research

\begin{abstract}
Abstrak. Kegiatan ini bertujuan untuk meningkatkan pemahaman guru-guru SDI Mbongawani Ende mengenai pelaksanaan seminar hasil penelitian tindakan kelas. Kegiatan ini juga bertujuan untuk membantu guru-guru tersebut mengumpulkan dokumen-dokumen pelaksanaan seminar sehingga dapat dijadikan sebagai bukti yang dilampirkan dalam berkas usulan kenaikan pangkat. Kegiatan ini diikuti oleh guru-guru dan kepala SDI Mbongawani, dosen, ketua gugus dan guru-guru dari gugus terkait. Kegiatan ini dilaksanakan melalui dua tahap, yakni tahap persiapan dan tahap pelaksanaan seminar. Pada setiap tahap, para guru dibimbing dan dilatih untuk mempersiapkan, melaksanakan dan mendokumenkan bukti-bukti seminar hasil penelitian tindakan kelas. Hasil kegiatan ini memberikan dampak pada peningkatan pemahaman guru-guru SDI Mbongawani mengenai pelaksanaan seminar hasil penelitian tindakan kelas.
\end{abstract}

Kata Kunci: Pendampingan, Seminar, Penelitin Tindakan Kelas.

How to Cite: Sariyyah, N., Restianim, V., Raji, M. N., Wangge, Y.S., \& Bito, G. S. (2021). Pendampingan Kegiatan Seminar Hasil Penelitian Tindakan Kelas Pada Guru-Guru SDI Mbongawani. Prima Abdika : Jurnal Pengabdian Masyarakat, 1(3), 91-97. https://doi.org/10.37478/abdika.v1i3.1208 Wangge, Gregorius Sebo Bito. This work is licensed under a Creative Commons AttributionShareAlike 4.0 International License.

\section{Pendahuluan}

Proses pembelajaran adalah suatu hal yang penting dalam sebuah pendidikan. Sejalan perkembangan masyarakat dewasa ini pendidikan banyak menghadapi berbagai tantangan, salah satunya berkenaan dengan peningkatan mutu pendidikan. Salah satu upaya untuk meningkatkan mutu pendidikan adalah dengan cara memperbaiki proses belajar mengajar. Belajar mengajar pada dasarnya adalah interaksi atau hubungan timbal balik antara guru dan peserta didik dalam situasi pendidikan (Muslihudin \& Arumita, 2006). Oleh karena itu, guru dalam mengajar dituntut kesabaran, keuletan dan sikap terbuka disamping kemampuan mengelola situasi belajar mengajar yang lebih aktif dan menarik. Sebab banyak fakta yang ditemukan dalam kelas-kelas belajar dimana terdapat banyak masalah yang dihadapi pada saat proses pembelajaran seperti hasil belajar siswa yang rendah, menurunnya motivasi dan aktivitas belajar siswa, dan lain-lain. Masalah-masalah tersebut membutuhkan solusi untuk dipecahkan. 
Menurut Santoso (Mahayanti \& Utami, 2017), penelitian tindakan kelas dapat menjadi salah satu alternatif pemecahan masalah pembelajaran. Hal ini dikarenakan penelitian tindakan diawali dengan refleksi. Proses ini memberikan peluang bagi guru untuk focus pada masalah terdekat yang dihadapi secara nyata dan mencari upaya penyelesaiannya. Dengan demikian, PTK merupakan upaya yang paling tepat dalam meningkatkan kualitas pembelajaran dan kemampuan siswa.

Kemampuan menyusun penelitian tindakan kelas merupakan salah satu kemampuan yang harus dimiliki guru professional (Sumarsono \& Syamsudin, 2019). Melalui penelitian tindakan kelas, guru dituntut untuk senantiasa melakukan refleksi diri tentang pelaksanaan proses pembelajaran yang dilakukannya untuk menemukan berbagai permasalahan yang dihadapi dan merencanakan berbagai tindakan yang dapat memecahkan masalah yang dihadapi tersebut. Kemampuan meneliti ini dibutuhkan guru untuk meningkatkan mutu pembelajaran secara terus menerus.

Menurut (Dwiprabowo \& Faujiah, 2021), penelitian tindakan kelas adalah salah satu evaluasi dari keseluruhan pembelajaran yang telah dilakukan oleh guru untuk merefleksi kegiatan pembelajaran serta pelaksanaannya dalam aktivitas pembelajaran untuk mencapai tujuan dari pendidikan. Dalam dunia pendidikan di Indonesia, penelitian tindakan kelas merupakan suatu hal yang baru digemakan dua dasawarsa terakhir. Namun sesungguhnya Penelitian Tindakan Kelas (PTK) bukanlah hal yang baru. Jenis penelitian ini sudah berkembang sejak tahun 1970-an atau bahkan sebelumnya (Wardani et al., 2019), perhatian yang besar para stake holder pendidikan di Indonesia pada PTK didasari oleh keyakinan bahwa upaya perbaikan atau peningkatan kualitas pembelajaran harus dilakukan oleh pelaku pembelajaran itu sendiri yang dalam hal ini adalah guru. Sehingga penelitian tindakan kelas turut menjadi bagian dalam meningkatkan profesionalitas guru.

Penelitian tindakan kelas memberikan dampak yang positif dalam peningkatan kualitas guru maupun siswa di sekolah sehingga dijadikan salah satu prasyarat dalam penilaian usulan kenaikan pangkat bagi guru. Sehingga para guru selalu berupaya untuk melaksanakan penelitian tersebut. namun hal tersebut tidak semulus seperti yang diharapkan dimana masih banyak guru-guru yang mengalami kendala dalam mengimplemntasikan jenis penelitian ini. Situasi ini terungkap dalam kegiatan pengabdian masyarakat yang sebelumnya dilakukan oleh Sar'iyyah (2021) maupun See et al (2021) pada sejumlah guru di kabupaten Ende yang kesulitan mengembangkan proposal maupun laporan hasil penelitian.

Permasalahan yang dihadapi guru-guru di kabupaten Ende tidak hanya terbatas pada kemapuan menyusun PTK namun yang telah berhasil menyusun dan mengimplementasikan PTK pun masih mengalami kendala dalam mempertanggungjawabkan laporannya secara ilmiah. Hal ini dialami oleh guru-guru di SDI Mbongawani yang sudah beberapa kali mengusulkan kenaikan pangkat namun laporan karya PTK mereka ditolak karena dianggap belum dipertanggungjawabkan secara ilmiah atau belum diseminarkan. Hal ini membuat para guru kebingungan karena belum memahami proses dan tata 
cara dalam menseminarkan hasil penelitian yang telah dibuat. Sehingga berdasarkan permasalahan tersebut, para guru perlu diberikan pendampingan dalam kegiatan seminar hasil penelitian tindakan kelas sebagai solusi dalam mengatasi permasalahan yang mereka hadapi.

\section{Metode Pelaksanaan}

Metode pelaksanaan kegiatan pengabdian ini terbagi atas tahap persiapan dan tahap pelaksanaan kegiatan seminar. Tahap persiapan merupakan kegiatan-kegiatan yang dilakukan sebelum pelaksanaan berlangung. Tahap persiapan dilakukan dengan membentuk panitia kegiatan seminar hasil penelitian tindakan kelas. Pembentukan panitia dilakukan seminggu sebelum kegiatan berlangsung. Berdasarkan kesepakatan, panitia penyelenggara diserahkan kepada pihak sekolah sementara pihak dosen bertugas sebagai pembanding dan pengawas jalannya kegiatan. Tahap persiapan lain yakni diakukan teknikal meeting dan gladi bersih sehari sebelum kegiatan dilaksanakan. Tahap pelaksanaan kegiatan dilakukan sesuai jalannya seminar pada umumnya yakni terdiri dari Kegiatan pembukaan, Presentasi hasil dan Kegiatan Penutup

\section{Hasil dan Pembahasan}

Proses pendampingan kegiatan seminar hasil penelitian tindakan kelas untuk guru-guru SDI Mbongawani secara umum dilakukan selama satu minggu. Proses tersebut meliputi tahap persiapan maupun tahap pelaksanaan. untuk mengetahui sejauhmana pemahaman para guru mengenai kegiatan seminar hasil penelitian tindakan kelas, dilakukan penyebaran angket sebelum tahap persiapan dilaksanakan. Terdapat 5 orang guru yang mengisi angket dimana rata-rata guru tersebut belum memahami prosedur seminar hasil penelitian tindakan kelas karena belum pernah melakukan kegiatan tersebut. Selain itu, para guru belum memahami dokumen-dokumen apa saja yang diperlukan sebagai bukti fisik telah dilaksanakan kegiatan seminar hasil PTK. Hal ini yang menjadi alasan usulan kenaikan pangkat mereka sering ditolak, sebab tidak memiliki bukti fisik atau dokumen-dokumen pendukung kegiatan seminar yang lengkap. Berdasarkan informasi yang diperoleh dari angket tersebut, maka dilakukan kegiatan tatap muka bersama para guru dan kepala sekolah guna membicarakan persiapan kegiatan dimaksud.

Persiapan awal dilakukan dengan memberikan pemahaman awal mengenai tata cara pelaksanaan seminar serta dokumen-dokumen yang diperlukan dalam pelaksanaan seminar. Pada pertemuan tersebut juga langsung dibentuk panitia kegiatan seminar yang diserahkan langsung ke pihak sekolah. Persiapan kedua merupakan gladi bersih yang dilaksanakan sehari sebelum kegiatan berlangsung. Proses gladi ini dilakukan atas permintaan guru dengan tujuan agar meminimalisir kekurangan-kekurangan yang mungkin saja dapat ditemui dalam pelaksanaan kegiatan seminar.

Pada tanggal 26 April 2021 dilakukan kegiatan seminar hasil penelitian tindakan kelas. Adapun peserta kegiatan terdiri dari 5 presentator, 1 orang pengawas, 5 orang dosen, kepala sekolah, ketua gugus, guru-guru SDI 
Mbongawani dan beberapa guru dari sekolah gugus terkait. Kegiatan pembukaan diawali dengan doa dan sambutan-sambutan yang kemudian diserahkan kepada moderator untuk memimpin jalannya kegiatan seminar.

Setelah dibuka oleh moderator, satu persatu peserta pun dipanggil untuk mempresentasikan hasil seminarnya. Dalam proses tersebut pengawas dan masing-masing dosen ditugaskan sebagai pembanding yang memberi masukan dan menilai hasil penelitian tindakan. Sedangkan beberapa orang guru ditugaskan untuk mencatat jalannya kegiatan seminar dan mengambil gambar selama proses seminar.

Adapun daftar judul PTK yang diseminarkan dan pembanding dapat dilihat pada Tabel 1 .

Tabel 1 Daftar judul PTK presentator dan pembanding

\begin{tabular}{|c|c|c|}
\hline Presentator & Judul PTK & Pembanding \\
\hline 1 & $\begin{array}{l}\text { Upaya meningkatkan hasil belajar } \\
\text { matematika materi pecahan } \\
\text { sederhana dengan media kartu } \\
\text { pecahan pada siswa kelas III SDI } \\
\text { Mbongawani Kecamatan Ende } \\
\text { Selatan }\end{array}$ & $\begin{array}{l}\text { 1. Pengawas } \\
\text { 2. Gregorius, Sebo Bito, } \\
\text { S.Pd., M.Pd } \\
\text { 3. Vivien Restianim, } \\
\text { S.Pd.,M.Si }\end{array}$ \\
\hline 2 & $\begin{array}{l}\text { Penerapan Metode Inquiri Untuk } \\
\text { Meningkatkan Hasil Belajar Peserta } \\
\text { didik dalam pembelajaran IPA } \\
\text { dengan materi Struktur Batang } \\
\text { Tanaman dengan fungsinya di kelas } \\
\text { IV SDI Paupanda } 2 \text { tahun pelajaran } \\
\text { 2018/2019 }\end{array}$ & $\begin{array}{l}\text { 1. Pengawas } \\
\text { 2. Vivien Restanim, } \\
\text { S.Pd.,M.Si } \\
\text { 3. Gregorius, Sebo Bito, } \\
\text { S.Pd., M.Pd }\end{array}$ \\
\hline 3 & 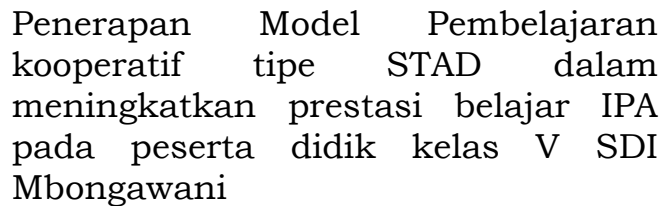 & $\begin{array}{l}\text { 1. Pengawas } \\
\text { 2. Nining Sar'iyyah, } \\
\text { S.Pd.,M.Pd } \\
\text { 3. Manggu Ngguna Raji }\end{array}$ \\
\hline 4 & $\begin{array}{l}\text { Peningkatan Hasil Belajar IPA materi } \\
\text { ciri-ciri khusus makhluk hidup hean } \\
\text { menggunakan model pembelajaran } \\
\text { kooperatif tipe Jigsa pada siswa kelas } \\
\text { VI semester I SDI Mbongaani } \\
\text { kecamatan Ende selatan tahun } \\
\text { pelajaran } 2018 / 2019\end{array}$ & $\begin{array}{l}\text { 1. Pengawas } \\
\text { 2. Nining Sar'iyyah, } \\
\text { S.Pd.,M.Pd } \\
\text { 3. Yuliani Sepe Wangge, } \\
\text { S.Pd.,M.Pd }\end{array}$ \\
\hline 5 & $\begin{array}{l}\text { Meningkatkan hasil belajar IPA } \\
\text { tentang penerapan sifat-sifat bunyi } \\
\text { melalui metode eksperimen pada } \\
\text { peserta didik kelas IV } \\
\text { Mbongawani }\end{array}$ & $\begin{array}{l}\text { 1. Pengawas } \\
\text { 2. Yuliani Sepe Wangge, } \\
\text { S.Pd.,M.Pd } \\
\text { 3. Manggu Ngguna Raji }\end{array}$ \\
\hline
\end{tabular}

Tabel 1 di atas merupakan data urutan presentator. Setiap sesi presentasi masing-masing peserta berdurasi 40 menit, dimana 10 menit untuk menyajikan presentasi dan 30 menit lainnya digunakan untuk tanya jawab dan memberi masukan terhadap isi PTK yang disajikan. Dalam kegiatan 
penyajian materi, beberapa guru terlihat menampilkan presentasi dengan media power point namun adapula guru yang menyajikan secara utuh isi penelitian dalam dokumen word sehingga beberapa kali dintervensi moderator agar membacakan poin-poin penting saja.



Gambar 1 Presentator sedang menyajikan presentasi

Dalam proses presentasi terdapat banyak pertanyaan, sanggahan maupun masukan-masukan terkait hasil PTK setiap presentator. Pertanyaanpertanyaan dan masukan umumnya terkait permasalahan dan judul PTK seperti jumlah kata pada judul yang terlalu panjang, kejelasan latar belakang masalah, kesesuaian data dengan teknik pengambilan data, temuan penelitian serta bukti-bukti penelitian. Rata-rata setiap presentator dapat menjawab dan mempertanggungjawabkan dengan baik. Pertanyaan-pertanyaan tersebut tidak hanya berasal pembanding. Beberapa peserta kegiatan yang berasal dari sekolah lain juga ikut memberikan pertanyaan dan masukan. Kegiatan ini dilaksanakan kurang lebih selama tiga jam yang kemudan dilanjutkan dengan kegiatan penutup.

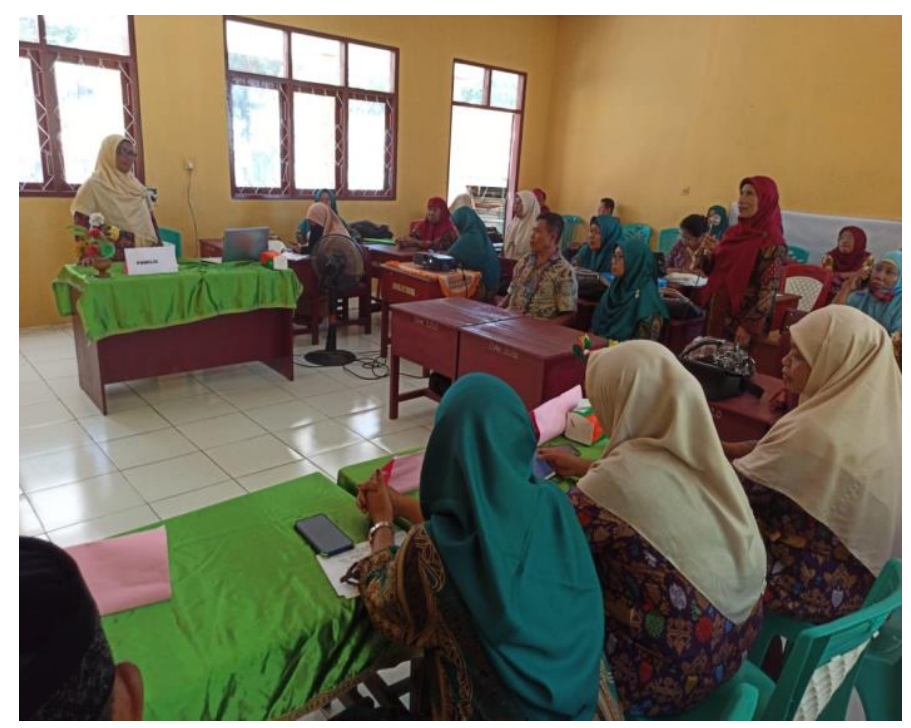


Gambar 2 Salah satu peserta bertanya kepada presentator



Gambar 3 Pembanding memberikan masukan kepada presentator

Pada kegiatan penutup, baik kepala sekolah maupun pengawas sepakat untuk melakukan secara rutin kegiatan ini. Pengawas menyampaikan agar guru-guru dapat melampirkan dengan rapi bukti-bukti dokumen kegiatan ini agar bisa dijadikan usulan kenaikan pangkatnya masing-masing. Pengawas juga berharap hasil penelitian yang telah diseminarkan guru-guru dapat dipublikasikan ke dalam artikel sehingga dapat lebih memiliki nilai dan manfaat lain bagi guru-guru ke depannya. Pada akhir acara, angket kembali disebar untuk mengetahui pemahaman para guru mengenai kegiatan seminar. Hasil angket menunjukkan bahwa para guru telah memahami dengan baik mengenai prosedur pelaksanaan seminar hasil penelitian tindakan kelas maupun persiapan-persiapan dokumen terkait yang dibutuhkan untuk usulan kenaikan pangkat .

Secara keseluruhan kegiatan ini telah berhasil dijalankan walaupun masih ditemukan beberapa kendala teknis. Kendala tersebut antara lain, masih ada guru yang belum bisa mengembangkan media presentasi yang baik. Hal ini disebabkan para guru tidak terbiasa menggunakan peralatan seperti komputer dan laptop sehingga agak kurang mahir mengoperasikan peralatan tersebut.

\section{Simpulan dan Tindak Lanjut}

Tujuan diadakannya kegiatan ini adalah untuk meningkatkan pemahaman guru-guru di SDI Mbongawani Ende mengenai prosedur pelaksanaan seminar hasil penelitian tindakan kelas. kegiatan ini telah berhasil dijalankan dengan baik dan menghasilkan bukti-bukti dokumen pelaksanaan seminar hasil penelitian yang dibutuhkan para guru untuk 
mengajukan usulan kenaikan pangkatnya. Kegiatan ini juga dihadiri oleh ketua gugus dan guru-guru dari sekolah-sekolah gugus terkait, sehingga untuk tindak lanjut ke depannya diharapkan kegiatan serupa dapat dilaksanakan pada tingkat gugus.

\section{Daftar Pustaka}

Dwiprabowo, R., \& Faujiah, E. (2021). PKM Pelatihan Penelitian Tindakan Kelas: Aspek Pokok Etika Penelitian dan Kriteria Penilaian pada Guru SD Negeri Jati Mekar 02 Bekasi. Prima Abdika: Jurnal Pengabdian Masyarakat, 1(2), 52-57. https://doi.org/10.37478/abdika.v1i2.939

Mahayanti, N. W. S., \& Utami, I. M. I. (2017). Pelatihan dan pendampingan penelitian tindakan kelas bagi guru bahasa inggris smp di kecamatan sukasada. Widya Laksana, 6(2), 145-155. https://ejournal.undiksha.ac.id/index.php/JPKM/article/view/11619

Muslihudin, M., \& Arumita, A. W. (2016). Pembuatan Model Penilaian Proses Belajar Mengajar Perguruan Tinggi Menggunakan Fuzzy Simple Additive Weighting (Saw)(Sudi: Stmik Pringsewu). Semnasteknomedia Online, 4(1), 4-11. https://ojs.amikom.ac.id/index.php/semnasteknomedia/article/view/ 1296

Sar'iyyah, N., Wangge, Y. S., Nono BS, Y., \& Bito, G. S. (2021). Pendampingan Penelitian Tindakan Kelas untuk Guru Sekolah Dasar di Kota Ende. Prima Abdika: Jurnal Pengabdian Masyarakat, 1(2), 34-41. https://doi.org/10.37478/abdika.v1i2.945

See, S., Sadipun, B., Wali, M., We'u, G., Abdullah, A. N., Pali, A., \& Arafat, S. (2021). Pelatihan Penyusunan Proposal PTK Kepada Para Guru Sekolah Dasar Di Gugus 3 Kabupaten Ende. Prima Abdika: Jurnal Pengabdian Masyarakat, 1(1), 7-13. https://doi.org/10.37478/abdika.v1i1.941

Sumarsono, A., \& Syamsudin. (2019). Peningkatan Kompetensi Penelitian Tindakan Kelas Melalui Metode Pelatihan, Penerapan Dan Pendampingan Bagi Guru Sekolah Satu Atap Wasur Di Kabupaten Merauke. Sarwahita, 16(02), 146-155. https://doi.org/10.21009/sarwahita.162.06

Wardani, W., Karsiwan, K., Purwasih, A., Lisdiana, A., \& Hammer, W. (2019). Pendampingan Pelaksanaan Penelitian Tindakan Kelas Dalam Meningkatkan Profesionalisme Guru Di Kabupaten Pringsewu. DEDIKASI: Jurnal Pengabdian Masyarakat, 1(2), 323-342. https://e-journal.metrouniv.ac.id/index.php/JPM/article/view/ 1762 